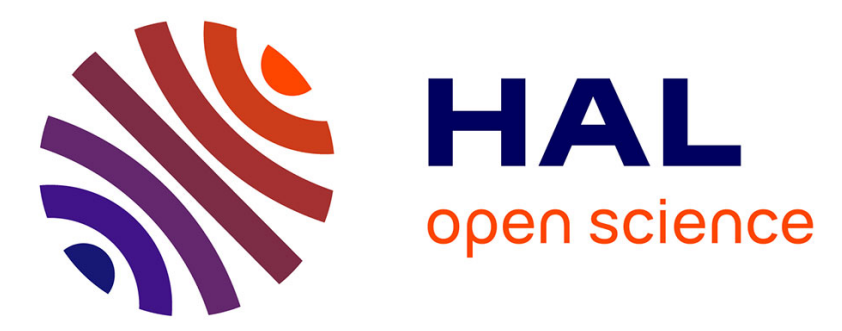

\title{
Development of a compression test device for investigating interaction between diffusion of biodiesel and large deformation in rubber
}

A. B. Chai, Andri Andriyana, Erwan Verron, M.R. Johan, A. S. M. A. Haseeb

\section{- To cite this version:}

A. B. Chai, Andri Andriyana, Erwan Verron, M.R. Johan, A. S. M. A. Haseeb. Development of a compression test device for investigating interaction between diffusion of biodiesel and large deformation in rubber. Polymer Testing, 2011, 30 (8), pp.867-875. 10.1016/j.polymertesting.2011.08.009 . hal-01006739

\section{HAL Id: hal-01006739 \\ https://hal.science/hal-01006739}

Submitted on 16 Jun 2014

HAL is a multi-disciplinary open access archive for the deposit and dissemination of scientific research documents, whether they are published or not. The documents may come from teaching and research institutions in France or abroad, or from public or private research centers.
L'archive ouverte pluridisciplinaire HAL, est destinée au dépôt et à la diffusion de documents scientifiques de niveau recherche, publiés ou non, émanant des établissements d'enseignement et de recherche français ou étrangers, des laboratoires publics ou privés. 


\title{
Development of a compression test device for investigating interaction between diffusion of biodiesel and large deformation in rubber
}

\author{
A.B. Chai ${ }^{a}$, A. Andriyana ${ }^{a}$, E. Verron ${ }^{b}$, M.R. Johan ${ }^{a}$, A.S.M.A. Haseeb ${ }^{a}$ \\ ${ }^{a}$ Department of Mechanical Engineering, University of Malaya, 50603 Kuala Lumpur, Malaysia \\ ${ }^{\mathrm{b}}$ Institut de Recherche en Génie Civil et Mécanique (GeM), UMR CNRS 6183 École Centrale de Nantes, BP 92101, 44321 Nantes, France
}

\begin{abstract}
Motivated by environmental and economic factors, biodiesel has been introduced to partially replace the diminishing stock of petroleum-based fuel. However, the use of biodiesel such as palm biodiesel is placing additional demands on automotive components, e.g. rubber components, due to a compatibility issue in the fuel system. In engineering applications where hostile environments are involved, the long-term mechanical response of rubber components is affected by interactions existed between diffusion of liquids into the material and fluctuating multiaxial loading. Hence, it is crucial to investigate the durability of rubber components in this aggressive environment. A number of studies on static immersion tests to investigate the diffusion of liquids in stress-free rubber can be found in the literature. However, studies focusing on the coupling between diffusion and large deformation in rubber, and the resulting swelling and mechanical response under cyclic loading conditions are less common. In the present work, a compression device for the investigation of interaction between diffusion of palm biodiesel and large compressive strain in rubber is developed. The apparatus is comprised of four rectangular stainless steel plates with spacer bars in between, which are designed such that pre-compression can be introduced on the rubber specimens while they are immersed into biodiesel. This allows diffusion and large strain to take place simultaneously. Different pre-compressive strains and biodiesel blends are considered. At the end of each immersion period, the resulting swelling behavior and mechanical response of rubber specimens under cyclic loading conditions are investigated. The features of this compression device are discussed and perspectives are drawn.
\end{abstract}

\author{
Keywords: \\ Rubber \\ Biodiesel diffusion \\ Large deformation \\ Compression \\ Mechanical response \\ Swelling
}

\section{Introduction}

Petroleum-based fuel is being depleted rapidly due to its limited reserve and increasing demand from various industries. The use of this type of fuel contributes significantly to the greenhouse effect resulting to environmental degradation. These problems as well as political concerns have encouraged the advancement in developing renewable sources such as biofuel as the alternative fuel. However, the introduction of biofuel which is derived from plant materials or animal fat is placing additional demands on the material compatibility in the fuel system [1-3]. Indeed, in the case of rubber, changes in fuel composition often create problems in rubber seals, pipes, gaskets and o-rings [4].

In sealing application, exposure of the rubber components to aggressive liquid in the container, such as organic solvent and oil, may lead to physical degradation of rubber. A major form of degradation in rubber exposed to liquid is swelling which can be described in terms of mass or volume change $[5,6]$. During the swelling process, liquids penetrate the polymer network and occupy positions 
among the polymer molecules. Consequently, the swelling of materials occurs when the macromolecules are forced apart. Furthermore, the mechanical stiffness decreases since the increase in chain separation will result in the reduction of secondary bonding [7]. In addition to exposure to potentially hostile environments, a large majority of rubber sealing components are simultaneously subjected to multiaxial mechanical loading in service conditions. Since these loading conditions impose generally fluctuating loads, the durability of rubber components becomes a critical issue.

The mechanical loading history, environment, rubber formulation and constitutive response are known to influence the durability of rubber components [8]. In the majority of studies involving fatigue of rubber, only the fatigue behavior in ambient (non-aggressive) environment is investigated. See for example the review of Mars and Fatemi [9] and the work of Verron and Andriyana [10], Andriyana et al. [11], Brieu et al. [12] among others. However, considerably fewer studies which explicitly deal with the fatigue failure analysis of rubber in aggressive environments are available [13-15]. A number of static immersion tests investigating the diffusion of liquid in stress-free rubber have been extensively studied (see Treloar [5] and references therein). However, investigations on more complex problems involving the swelling of polymer network in the presence of stresses (strains), in particularly multiaxial stress state, are less common. The earliest work dealing with the problem dates back to the work of Flory and Rehner [16]. Since this pioneering work, more recent accounts on coupling diffusion-large deformation can be found in the literature [17-22]. It can be noted that these studies deal with the interaction between diffusion of liquid and large deformation without explicitly relating them to cyclic and fatigue response of rubber.

The present work can be regarded as a first step towards an integrated durability analysis of industrial rubber components exposed to aggressive environments, e.g. oil environment in biofuel systems, during their service. To this end, a compression device is developed in order to observe the interaction between diffusion of liquids and large deformation in rubber. More precisely, the resulting swelling and mechanical responses under cyclic loading are investigated. Two types of rubber are considered: nitrile butadiene rubber (NBR) and polychloroprene rubber (CR).

This paper is organized as follows. In Section 2, experimental work including materials, specimen geometry, development of a compression device and the types of test conducted in this study are detailed. The experimental results are presented and discussed in Section 3. Concluding remarks are given in Section 4.

\section{Experimental program}

\subsection{Materials}

Commercial grades of NBR and CR with 60 Shore hardness were purchased from MAKA Engineering Sdn. Bhd., Malaysia. Different biodiesel blends were prepared by blending palm biodiesel (provided by Am Biofuels Sdn. Bhd., Malaysia) with diesel. Table 1 shows the analysis
Table 1

Properties of B100 palm biodiesel.

\begin{tabular}{llll}
\hline Test & Unit & Methods & Results \\
\hline Ester content & $\%(\mathrm{~m} / \mathrm{m})$ & EN 14103 & 96.9 \\
Density at $15{ }^{\circ} \mathrm{C}$ & $\mathrm{kg} / \mathrm{m}^{2}$ & EN ISO 12185 & 875.9 \\
Viscosity at $40{ }^{\circ} \mathrm{C}$ & $\mathrm{mm}^{2} / \mathrm{s}$ & EN ISO 3104 & 4.667 \\
Flash point & ${ }^{\circ} \mathrm{C}$ & EN ISO 3679 & 168 \\
Cetane number & - & EN ISO 5165 & 69.7 \\
Water content & $\mathrm{mg} / \mathrm{kg}$ & EN ISO 12937 & 155 \\
Acid value & $\mathrm{mgKOH} / \mathrm{g}$ & EN ISO 3679 & 0.38 \\
Methanol content & $\%(\mathrm{~m} / \mathrm{m})$ & EN 14110 & $<0.01$ \\
Monoglyceride content & $\%(\mathrm{~m} / \mathrm{m})$ & EN 14105 & 0.67 \\
Diglyceride content & $\%(\mathrm{~m} / \mathrm{m})$ & EN 14105 & 0.2 \\
Triglyceride content & $\%(\mathrm{~m} / \mathrm{m})$ & EN 14105 & 0.2 \\
Total glycerine & $\%(\mathrm{~m} / \mathrm{m})$ & EN 14105 & 0.25 \\
\hline
\end{tabular}

report of the palm biodiesel investigated. The palm biodiesel blends prepared were B0 (100\% diesel), B25 (blend of $25 \%$ of biodiesel and $75 \%$ of diesel), B75 (blend of $75 \%$ of biodiesel and 25\% of diesel) and B100 (100\% biodiesel).

\subsection{Specimen geometry}

To investigate the interaction between diffusion of biodiesel and large compressive strains in rubber, hollow cylindrical rubber specimens were used. Since the specimen will be subjected to compressive loading, the wall thickness should be large enough to avoid buckling. At the same time, it should be thin enough to ensure that equilibrium diffusion (swelling) can be achieved within a reasonable period of time. For this purpose, an annular rubber specimen having height, outer diameter and wall thickness of $10 \mathrm{~mm}, 50 \mathrm{~mm}$ and $6 \mathrm{~mm}$ respectively was considered in the present study.

\subsection{Compression device}

The rubber specimens described in the previous subsection were subsequently compressed to different levels of strain by fitting them into a specially designed device prior to immersion as shown in Fig. 1.

The compression device has the following special features:

1. It consists of four rectangular stainless steel plates. Stainless steel was used for corrosion resistance because the device needed to be immersed in diesel and biodiesel which are deemed to be corrosive.

2. The device is able to accommodate a total of 12 specimens arranged in three different levels between successive pairs of plates.

3. Each plate has four main holes to allow the liquid to flow and diffuse into the inner surface of the rubber specimens. In this way, each rubber specimen is subjected to diffusion of liquid from both inner and outer wall surfaces, i.e. diffusion occurs only along the radial direction as illustrated in Fig. 2.

4. For each level between two successive plates, a precompressive strain is applied to the specimens located at the corresponding level: $20 \%$ for level $1,10 \%$ for level 2 and $2 \%$ for level 3 . These different pre-compressive 


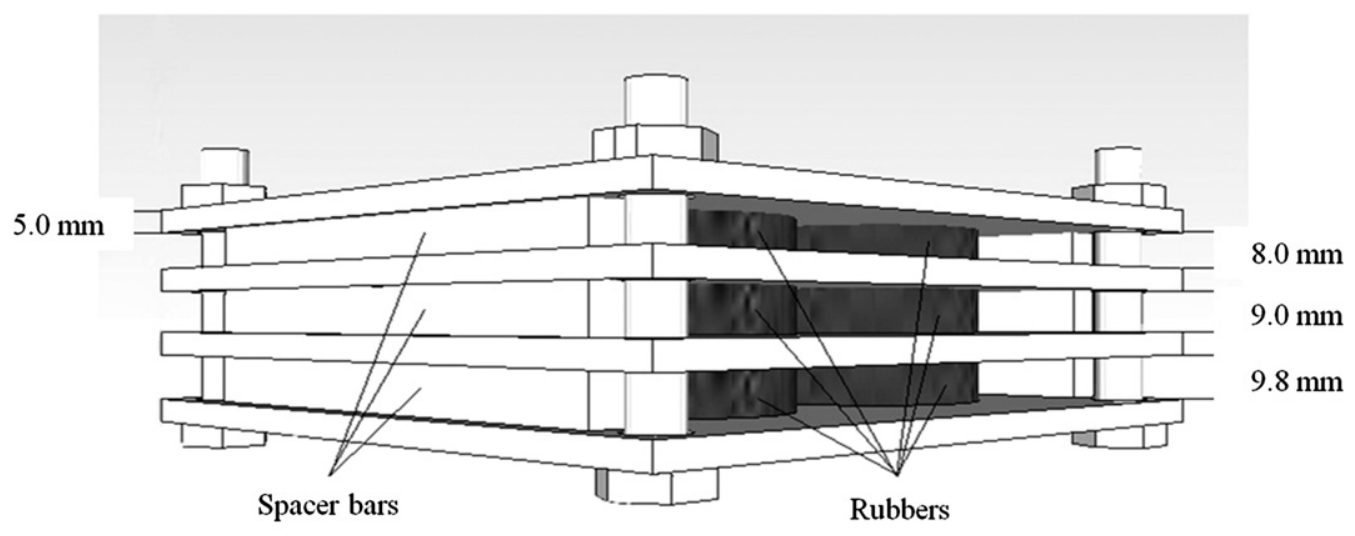

Front view

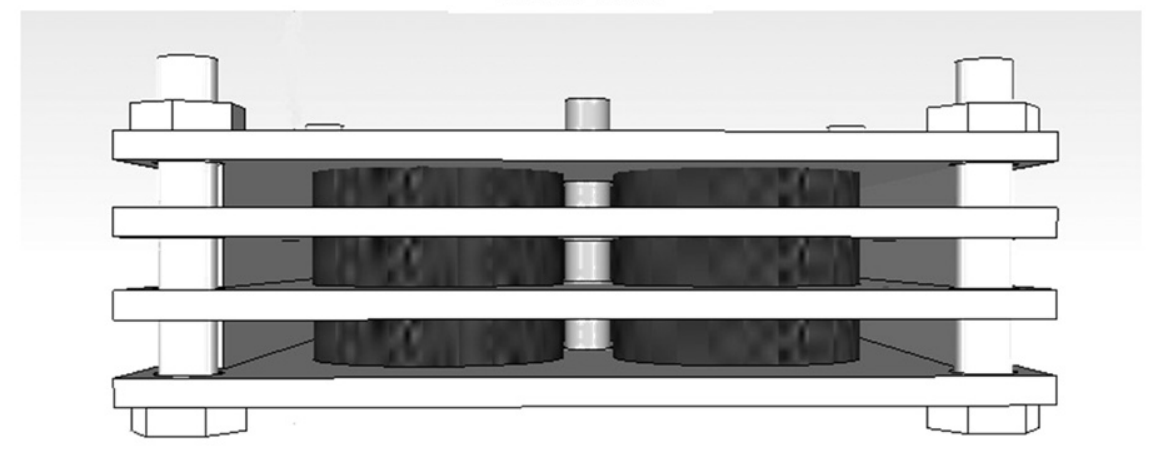

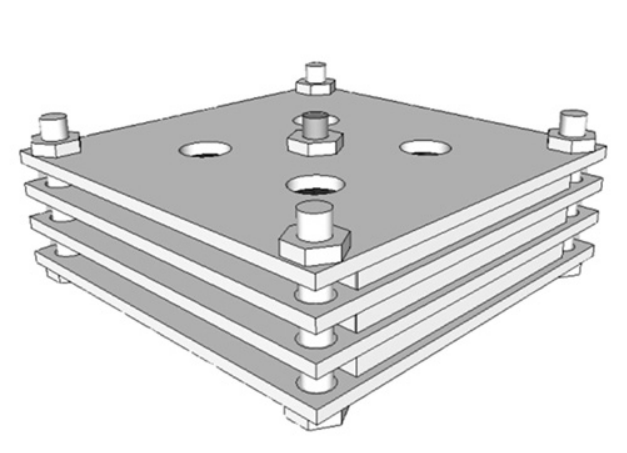

Edge view

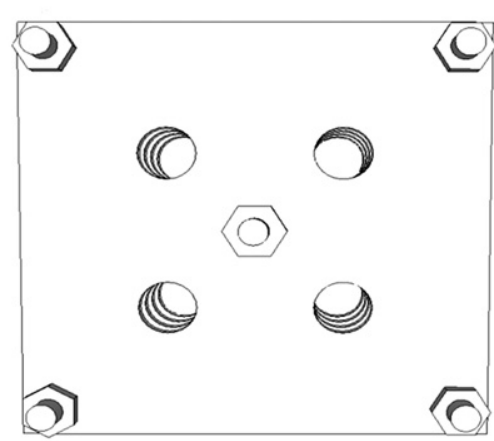

Top view

Fig. 1. Compression device.

strains are ensured by using spacers of appropriate height. Bolts and nuts located at each corner of the plates are used to tighten the device until the compression plates are uniformly in contact with the

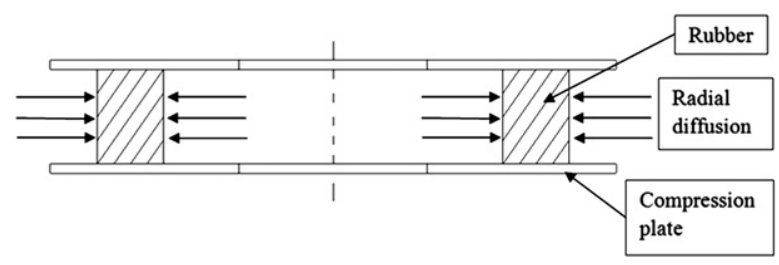

Fig. 2. Diagram of radial diffusion of biodiesel into rubber specimen under pre-compressive strain. spacers. Additional ring spacers are placed around the bolt in the middle of the plates to prevent bending of the plates.

5. In practice, $2 \%$ pre-compressive strain is so small that its effect on the macroscopic mechanical response is negligible. Nevertheless, this level of strain is retained to represent initially stress-free condition while ensuring that the diffusion occurred only along the radial direction.

Note: It is important to remember that the word "strain" used in this study corresponds to the engineering strain defined with respect to the unswollen-unstrained configuration. 


\subsection{Swelling measurement}

To investigate the effect of interaction between diffusion of biodiesel and large compressive strain on swelling behavior, the mass change and volume change exhibited by the specimens were measured. The test procedures for swelling measurement can be summarized as followed:

1. Before the immersion, the weight of the rubber specimen was measured in air and in distilled water. The specimen was then quickly dipped into alcohol and blotted dry with filter paper.

2. After weight measurement, the rubber specimens were placed in sequence on the compression plates. Grease was applied on the surface of the specimens that were in contact with the compression plate to avoid bulging and hence ensuring that the specimens were in a simple uniaxial compressive stress state.

3. Bolts and nuts were used to tighten the compression device until the compression plates were uniformly in contact with the spacers. The device containing rubber specimens was subsequently immersed in different palm biodiesel blends for different durations. The details of the immersion tests are given in Table 2. All the tests were conducted at room temperature.

4. At the end of each immersion period, the specimens were removed from the compression device and quickly dipped into acetone; they were then cleaned with filter paper to remove the oil excess. Specimens were left for 30 min to allow for recovery before any measurement was made after immersion.

5. Step 1 was repeated to measure the weight of rubber specimens after immersion.

The percentage of mass change and volume change were calculated using the following relations [4]:

$\%$ Mass change $=\frac{M_{2}-M_{1}}{M_{1}} \times 100$

$\%$ Volume change $=\frac{\left(M_{2}-M_{4}\right)-\left(M_{1}-M_{3}\right)}{\left(M_{1}-M_{3}\right)} \times 100$

where $M_{1}$ and $M_{2}$ are the mass in air (gram) before and after immersion while $M_{3}$ and $M_{4}$ are mass in water (gram) before and after immersion. For each biodiesel content, precompressive strain and immersion duration, at least four specimens were used to measure volume and mass changes.

\subsection{Mechanical response measurement}

To gain insight into the effect of coupled diffusion and large deformation on the mechanical response of the rubber

Table 2

Immersion tests.

\begin{tabular}{lll}
\hline $\begin{array}{l}\text { Biodiesel } \\
\text { blend }\end{array}$ & $\begin{array}{l}\text { Level of Compressive } \\
\text { strain (\%) }\end{array}$ & $\begin{array}{l}\text { Immersion } \\
\text { duration (days) }\end{array}$ \\
\hline B0 & $2 / 10 / 20$ & $30 / 90$ \\
B25 & $2 / 10 / 20$ & $30 / 90$ \\
B75 & $2 / 10 / 20$ & $30 / 90$ \\
B100 & $2 / 10 / 20$ & $30 / 90$ \\
\hline
\end{tabular}

under cyclic loading condition, mechanical measurements on the dry and swollen rubber specimens were carried out using an Instron 5500 uniaxial test machine equipped with $10 \mathrm{kN}$ load cell at room temperature. Circular compression plates were attached to the machine to ensure uniform displacement control on the specimens. The experimental setup was connected to a computer to record the experimental data. The test was conducted in compression at a constant displacement rate of $0.1 \mathrm{~mm} / \mathrm{s}$ to avoid excessive increase in the temperature of the specimens, i.e. thermal effects are not considered in the present study. The specimen was subjected to cyclic compressive loading at two different maximum compressive strains: $30 \%$ and $40 \%$ of 6 cycles each. To ensure repeatability of the results, at least three specimens were used to perform each test.

\section{Results and discussion}

\subsection{Swelling}

Figs. 3-6 show the percentage mass volume change of NBR and CR for different pre-compressive strains (2\%, $10 \%$
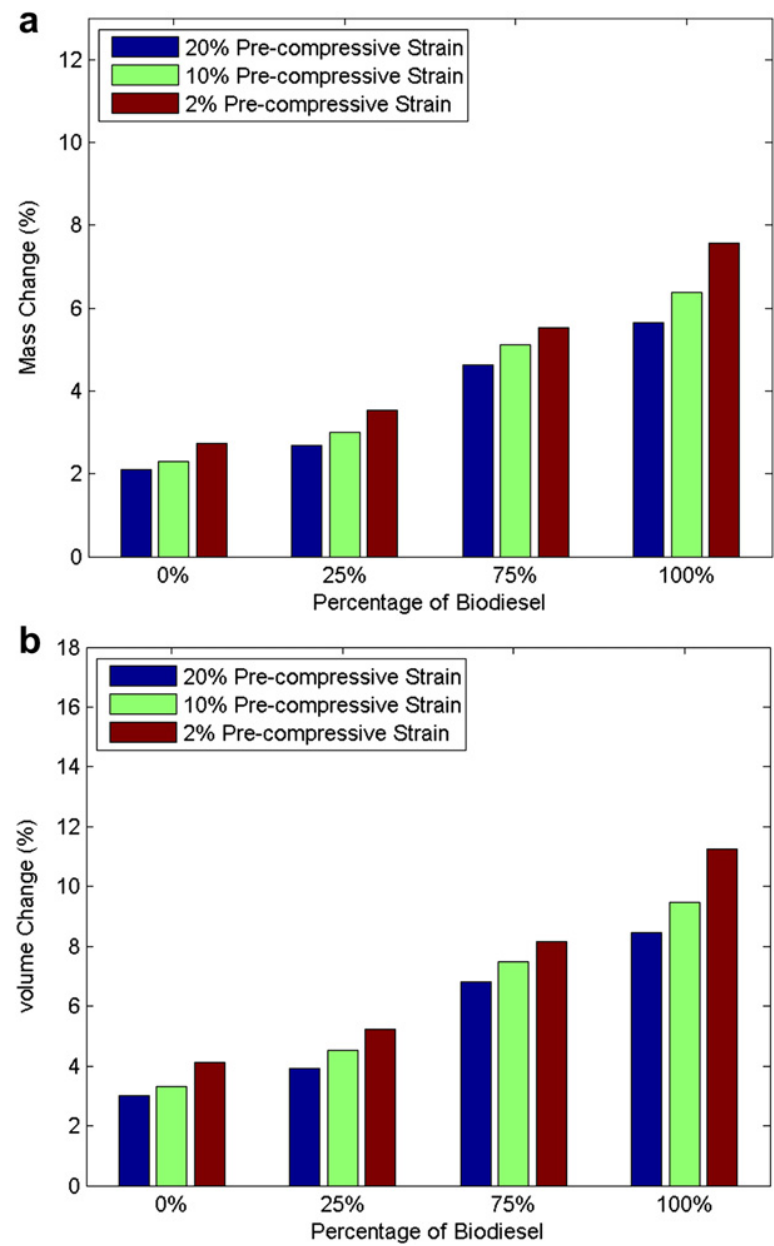

Fig. 3. (a) Mass change and (b) volume change of NBR at different compressive strains after 30 days immersion in different percentage of biodiesel blends. 
a

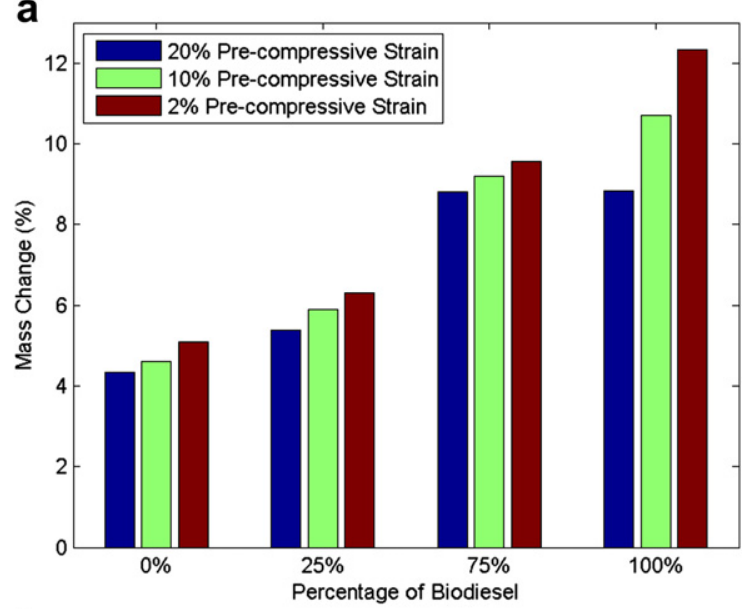

b

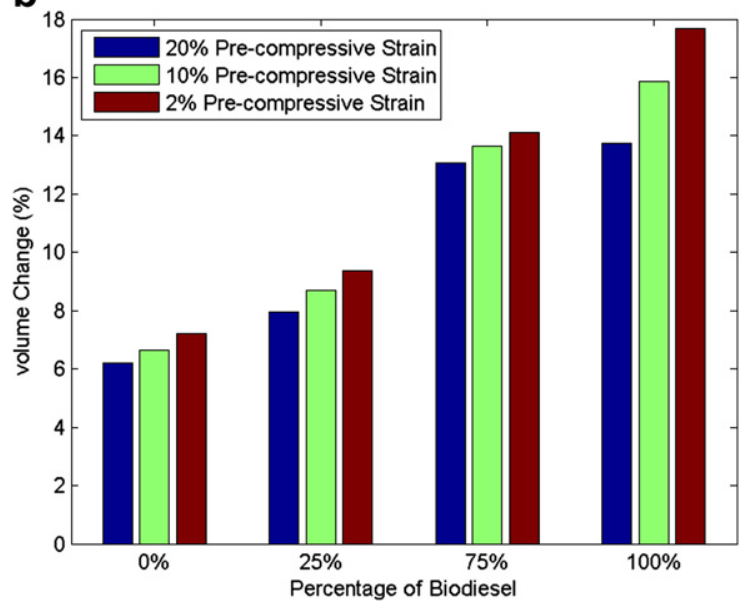

Fig. 4. (a) Mass change and (b) volume change of NBR at different compressive strains after 90 days immersion in different percentage of biodiesel blends.

and 20\%) after immersion in different biodiesel blends (B0, B25, B75 and B100) for 30 days and 90 days, respectively. All the plots show similar patterns. Both NBR and CR show increase in mass and volume change when the exposure time is increased from 30 days to 90 days. Swelling began with absorption of liquid into the surface layer of the rubber (adsorption) until a certain concentration and was followed by further penetration of liquid into the rubber by diffusion until the sample achieved equilibrium swelling [23].

The percentage of fuel uptake increased with the increase of palm biodiesel content. It is clear that for low biodiesel content (B0 and B25) no significant fuel uptake (less than $10 \%$ mass and volume change) is recorded for NBR. At the higher percentage of biodiesel content (B100), both NBR and CR show significant mass and volume change. The corresponding trend can be attributed to the segmental mobility of the polymer and free volume of the polymer [24].

Generally, it is also observed that the fuel uptake is affected by the level of pre-compression. The increase of pre-compressive strain restricted the fuel uptake into the elastomeric materials, i.e. the compressive stress appears to reduce the amount of swelling compared with that for a
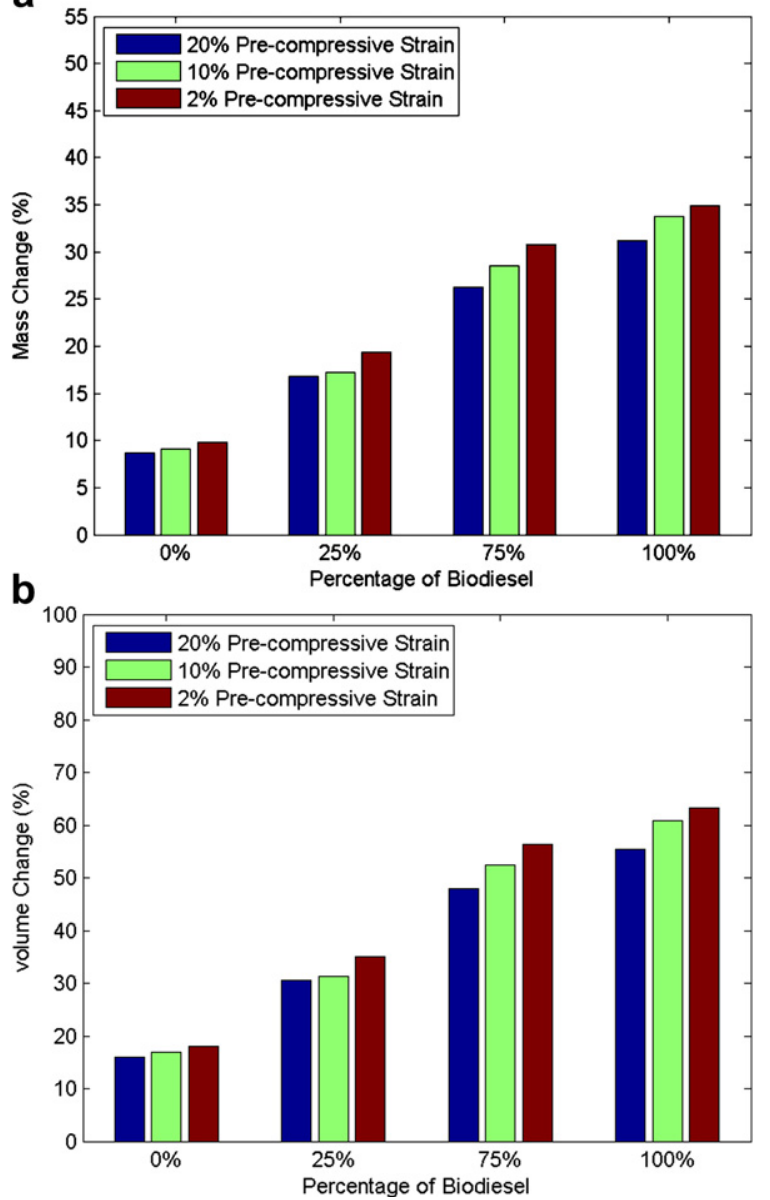

Fig. 5. (a) Mass change and (b) volume change of CR at different compressive strains after 30 days immersion in different percentage of biodiesel blends.

stress free rubber. As the compressive strain increases, the initial effective area for diffusion to occur along the radial direction in hollow cylindrical rubber specimens becomes smaller. Hence, the resulting swelling is lower. Furthermore, the reduction in swelling of rubber is affected by the hydrostatic component of the applied stress [5,25]. According to the authors, a compressive stress, for which the hydrostatic component is positive, leads to a decrease in the swelling of rubber. In the next subsection, only results that correspond to $2 \%$ pre-compressive strain are presented since the pre-compressive strain of $2 \%$ yields the highest level of swelling.

\subsection{Influence of swelling on the mechanical response of the rubbers}

The stress-strain curves of NBR and CR corresponding to $2 \%$ pre-compressive strain after immersion in B100 under cyclic compressive loading at two different maximum compressive strains are illustrated in Fig. 7. To compare the mechanical response of the swollen rubber with the dry rubber (unswollen), the compressive stress of the swollen specimen (after immersion) is computed by dividing the 
a

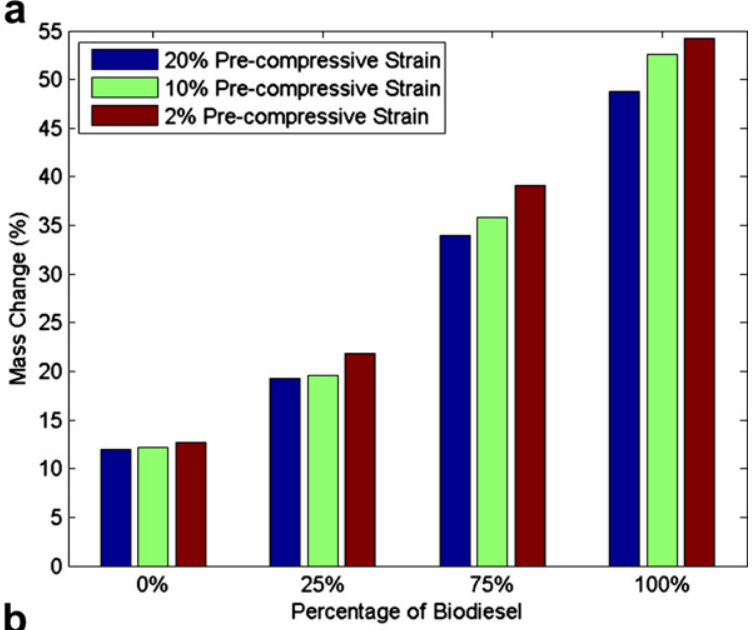

b

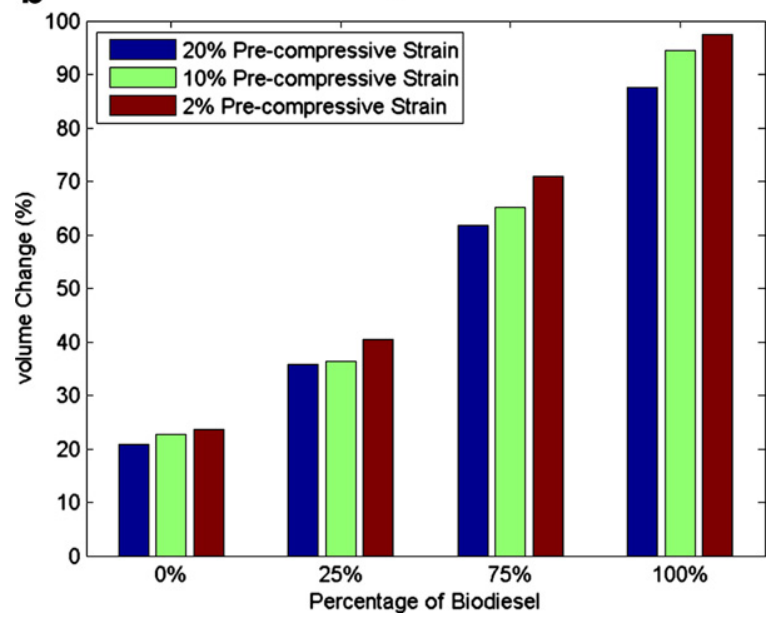

Fig. 6. (a) Mass change and (b) volume change of CR at different compressive strains after 90 days immersion in different percentage of biodiesel blends.

measured compressive force with the unswollen-unstrained cross section. For each maximum compressive strain, the specimen experiences six cycles of loading. It is shown that there is not much difference in the nature of stress-strain behavior after immersion. However, lower stress is recorded for swollen rubbers than dry ones. Moreover, increasing immersion duration appears to decrease further the stress level, i.e. higher swelling leads to lower stress. The corresponding behavior can be related to strong interaction of rubber-solvent matrix system [26].

Under cyclic loading conditions, both dry NBR and CR exhibit significant inelastic responses, i.e. mechanical hysteresis and stress-softening. The former is related to the amount of energy loss during a cycle and in the case of dry rubber can be related to viscoelasticity [27], viscoplasticity [28] or strain-induced crystallization [29]. The latter, characterized by the decrease in stress in the uploading during the first cycles, was first observed by Bouasse and Carrière [30] then intensively studied by Mullins [31]. It is often referred to as the Mullins effect. Despite a number of works devoted to the understanding of this stresssoftening, no general agreement has been found either on a

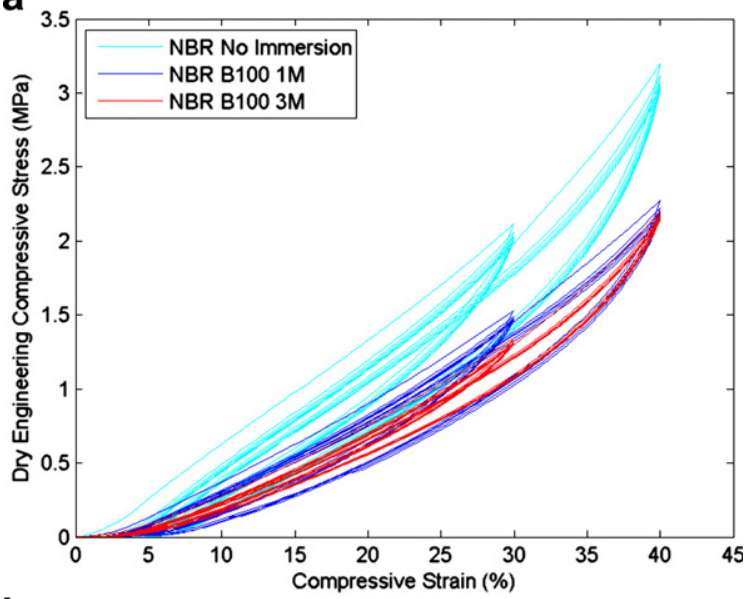

b

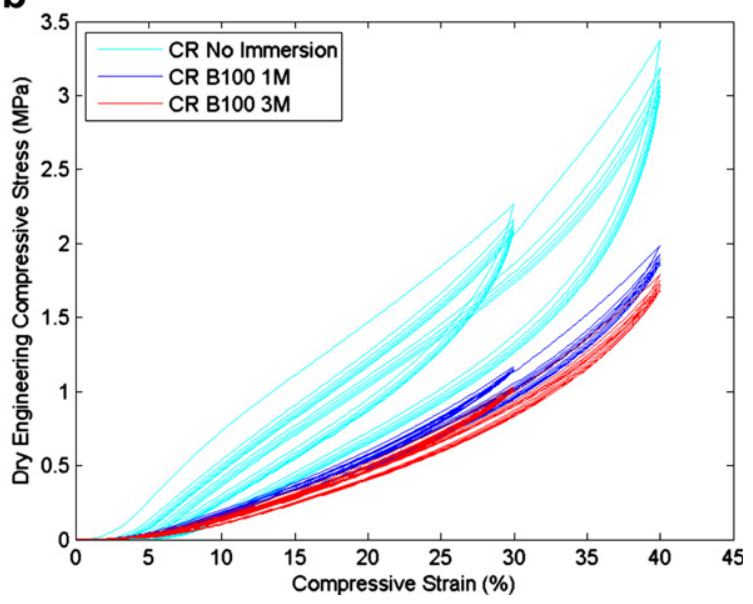

Fig. 7. Stress-strain curves of (a) NBR and (b) CR at dry states (without immersion) and after 30 days ( $1 \mathrm{M})$ and 90 days (3M) immersion in B100. Results correspond to pre-compressive strain of $2 \%$. For immersed rubbers, the stress is expressed with respect to unswollen-unstrained configuration (dry cross section).

the physical source or on the mechanical modeling of this softening at the microscopic or mesoscopic scales [32]. When NBR and CR are in a swollen state, the above inelastic responses decrease significantly, i.e. smaller hysteresis and stress-softening are observed. The next subsection focuses only on stress responses that correspond to maximum cyclic compressive strain of $30 \%$.

\subsection{Nature of swelling}

According to Treloar [5], swelling in rubber is a purely mixing or interdiffusion process with no chemical attraction between rubber and liquid molecules. Furthermore, the only effect of swelling is to reduce the modulus in inverse proportion to the cube root of the swelling ratio without changing the form of the stress-strain curves, i.e.,

$\frac{G}{G_{0}}=v_{2}^{\frac{1}{3}}$ 
where $G$ and $G_{0}$ are the shear modulus in swollen and dry states respectively, and $v_{2}$ is the volume fraction of rubber in the mixture of rubber and liquid. It is related to the change of volume in rubber, $\Delta V$ due to the presence of liquids via the following equation:

$v_{2}=\frac{1}{1+\Delta V}$

In the next paragraphs, the nature of swelling experienced by NBR and CR due to the presence of biodiesel is investigated, i.e. we examine if it follows swelling in the sense of Treloar [5] mentioned previously. For this purpose, the values of $G$ and $G_{0}$ are required. Unlike rubber materials considered in Treloar [5] which follow the neo-Hookean hyperelastic response, our materials exhibit strong inelastic responses as clearly depicted in Fig. 7. For this reason, the following methods were used for the determination of the shear modulus ratio:

1. Method 1 (M-1): The shear modulus ratio is calculated via the cube root of the swelling ratio as predicted by Treloar (Eq. (3)).

a

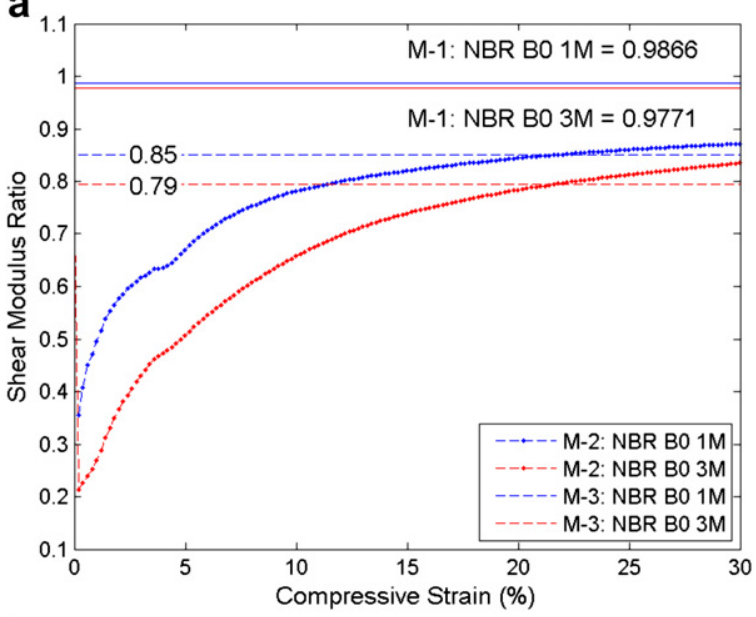

b

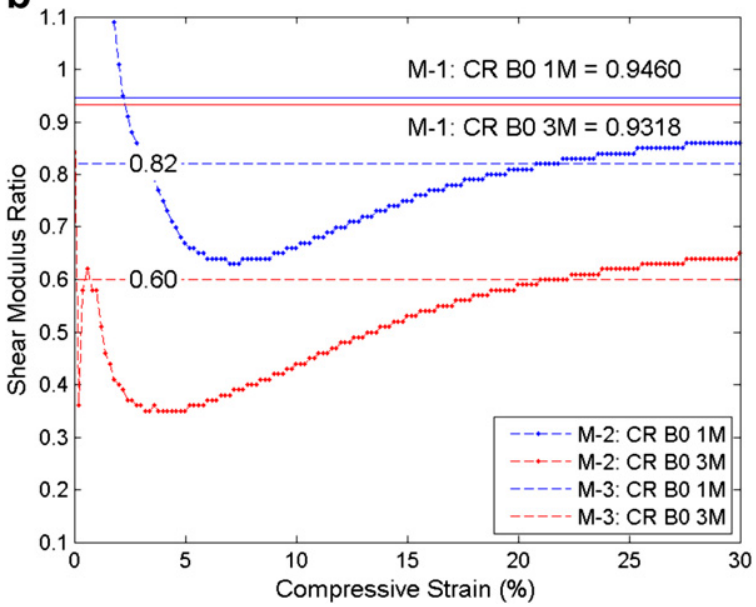

Fig. 8. Shear modulus ratio obtained using $\mathrm{M}-1, \mathrm{M}-2$ and $\mathrm{M}-3$ methods as a function of applied compressive strain for (a) NBR and (b) CR after immersed in B0. Results correspond to $2 \%$ pre-compressive strain.
2. Method 2 (M-2): $G$ and $G_{0}$ are identified by fitting the first uploading stress response of swollen and dry rubbers respectively. In both rubbers, the first uploading stress response is assumed to follow a simple neoHookean hyperelastic model.

3. Method 3 (M-3): The shear modulus ratio is calculated by dividing the first uploading stress response of swollen rubber with the one that corresponds to dry rubber, thereby allowing the observation of possible straindependent shear modulus ratio.

4. Method $4(\mathrm{M}-4): G$ and $G_{0}$ are identified by fitting the estimated equilibrium stress response of swollen and dry rubbers respectively. Following Bergström and Boyce [27], the equilibrium stress response is given by the imaginary curve lines between the uploading and unloading of the 6th cycle, i.e. after the stress-softening effect is removed. Here, the equilibrium response is also assumed to follow a simple neo-Hookean hyperelastic model.

5. Method 5 (M-5): The shear modulus ratio is calculated by dividing the estimated equilibrium stress response of

a

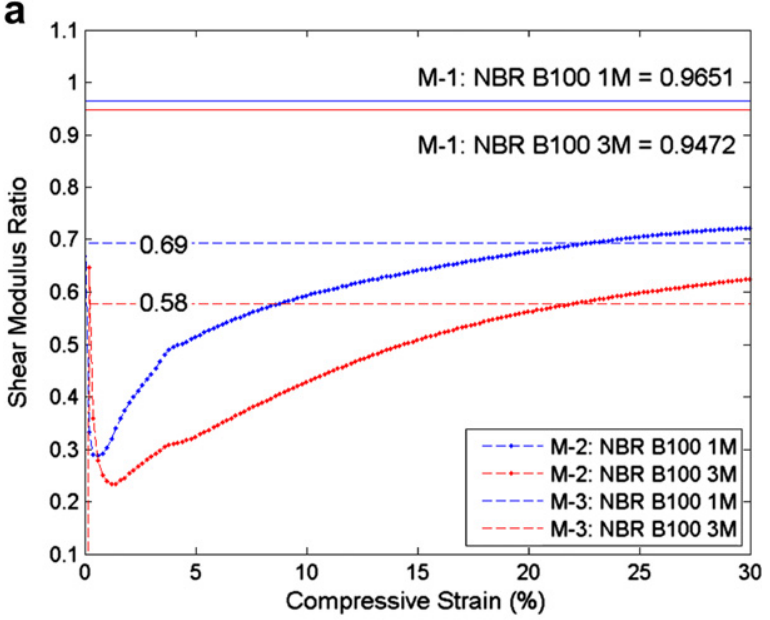

b

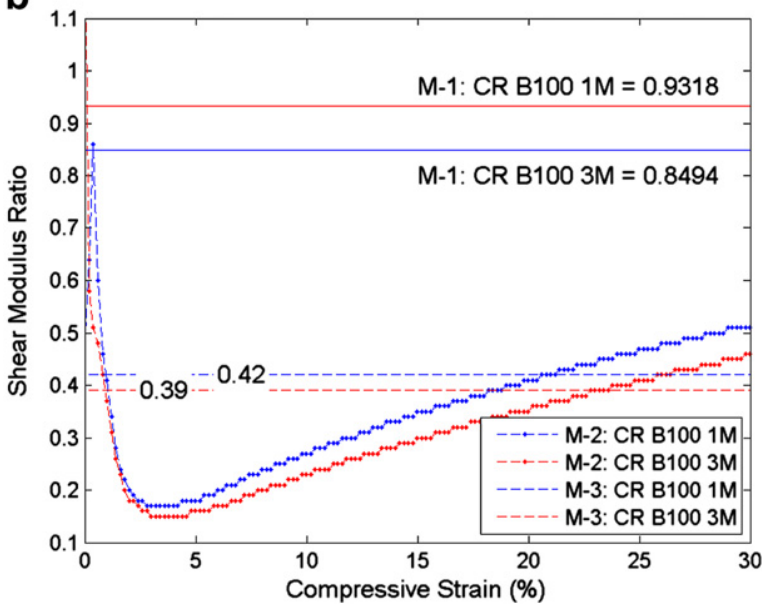

Fig. 9. Shear modulus ratio obtained using $M-1, M-2$ and $M-3$ methods as a function of applied compressive strain for (a) NBR and (b) CR after immersed in B100. Results correspond to $2 \%$ pre-compressive strain. 
swollen rubber with the one that corresponds to dry rubber. Similarly to M-3, this method also allows the observation of possible strain-dependent shear modulus ratio.

The five methods above are compared. In Figs. 8 and 9, shear modulus ratio obtained using $\mathrm{M}-1, \mathrm{M}-2$ and $\mathrm{M}-3$ methods are plotted as a function of applied compressive strain for NBR and CR immersed in B0 and B100 respectively. In each graph, results that correspond to 30 days $(1 \mathrm{M})$ and 90 days (3M) immersion are presented. Similarly, in Figs. 10 and 11, shear modulus ratio are plotted, but this time using $\mathrm{M}-1, \mathrm{M}-4$ and $\mathrm{M}-5$ methods.

In general, as depicted in Figs. 8-11, it is found that the shear modulus ratio deviates from the cube root of the swelling ratio as predicted by Treloar, i.e. results obtained using M-2, M-3, M-4 and M-5 methods are different from those resulting from M-1. Regardless of the type of rubbers and the methods considered, the deviation from Treloar theory in the shear modulus ratio resulting from immersion

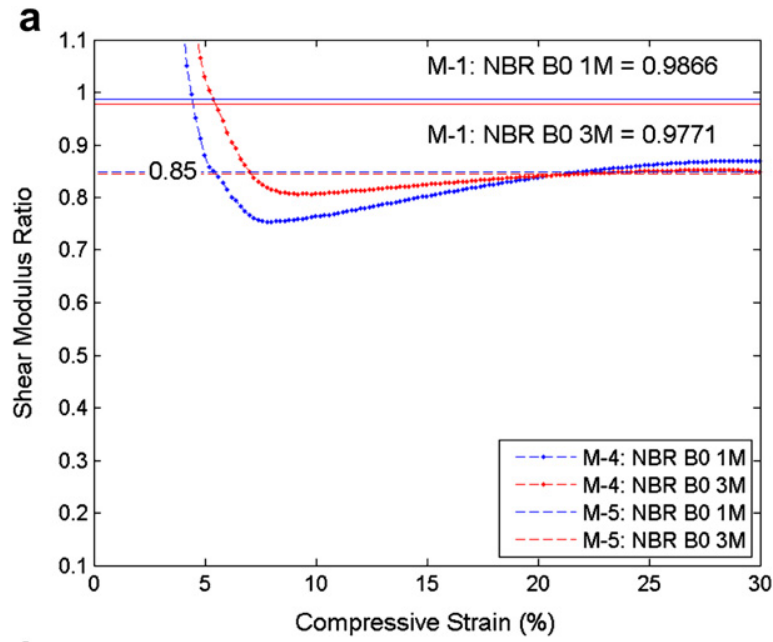

b

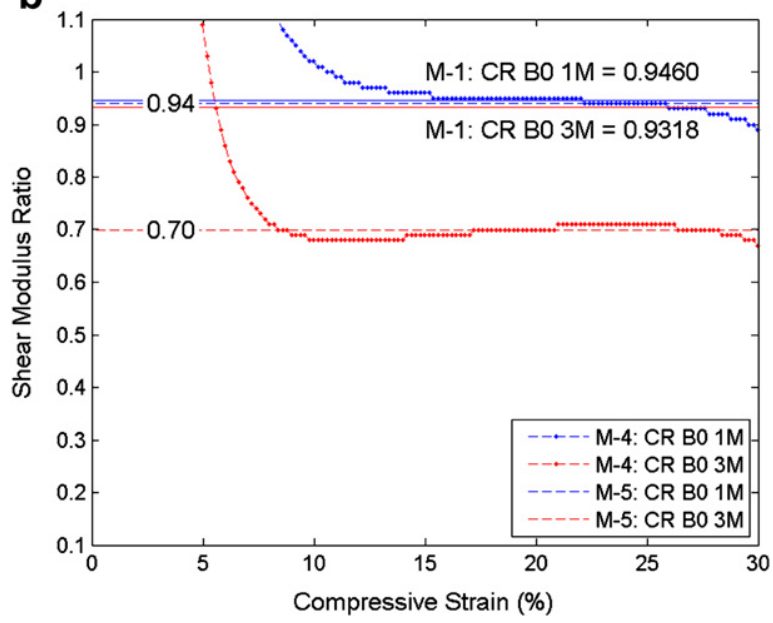

Fig. 10. Shear modulus ratio obtained using $M-1, M-4$ and $M-5$ methods as a function of applied compressive strain for (a) NBR and (b) CR after immersion in B0. Results correspond to $2 \%$ pre-compressive strain.
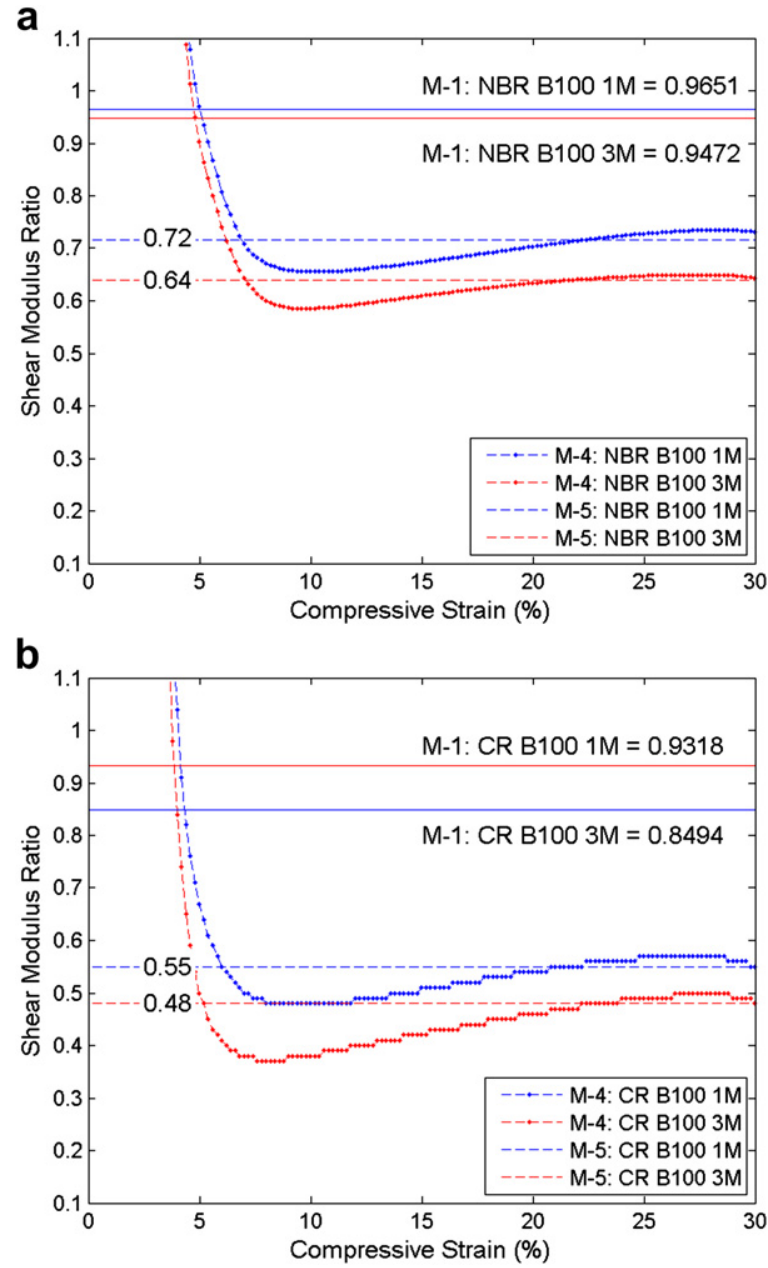

Fig. 11. Shear modulus ratio obtained using $M-1, M-4$ and $M-5$ methods as a function of applied compressive strain for (a) NBR and (b) CR after immersed in B100. Results correspond to $2 \%$ pre-compressive strain.

in B100 is systematically larger than the one resulting from immersion in B0. This observation suggests that stronger interaction occurs between rubbers and B100 than between rubbers and B0. Increasing the duration of immersion from 1 month to 3 months also increases the corresponding deviation. Finally, it is found that the shear modulus ratios calculated using the estimated equilibrium stress response, i.e. M-4 and M-5, appear to give closer values to the one predicted by Treloar than using the first uploading stress response, i.e. $\mathrm{M}-2$ and $\mathrm{M}-3$.

The deviation from Treloar theory can be attributed to the fact that Treloar assumes rubber networks to follow a hyperelastic Gaussian statistical model. In our case, as clearly shown in Fig. 7, our materials exhibit strong inelastic response. Hence, the use of hyperelastic assumption becomes questionable. Furthermore, unlike Treloar theory, the swelling phenomenon in NBR and CR due to the presence of biodiesel might also involve strong chemical interaction between rubbers and biodiesel. However, this statement cannot be fully verified in the present study. 


\section{Conclusions}

A simple test device for the analysis of the interaction between diffusion of liquids and large deformation in rubber was developed. The device consists of four stainless steel plates with spacer bars in between. The presence of spacer bars allows the application of pre-compressive strain while simultaneously exposing rubber specimens to biodiesel. It was found that the swelling in rubbers increases with the increase of palm biodiesel content and decreases with the increase of pre-compressive strain.

The effect of the presence of biodiesel on the mechanical response of rubber was also studied. It was observed that the presence of biodiesel and the increase in its content reduce significantly the mechanical strength of the rubber. Moreover, the inelastic responses decreased significantly due to the presence of biodiesel. The evolution of shear modulus ratio of swollen and dry rubbers as a function of applied compressive stress was investigated. It was found that this ratio deviates from the one predicted by Treloar. Finally, it should be noted that only uniaxial stress state was considered in the present study. Further investigation on the effect of multiaxial stress on the diffusion of liquids into rubber is needed.

\section{Acknowledgements}

The authors greatly appreciate the financial support of this research from Institute of Research Management and Consultancy, University of Malaya under University Research Grant (Grant No: RG083/10AET). This work was also partially funded by the Ministry of Higher Education Malaysia through High Impact Research Grant HIR-MOHE D000008-16001.

\section{References}

[1] M.A. Fazal, A.S.M.A. Haseeb, H.H. Masjuki, Biodiesel feasibility study: an evaluation of material compatibility; performance; emission and engine durability, Renew. Sust. Energ. Rev. 15 (2010) 1314-1324.

[2] A.S.M.A. Haseeb, H.H. Masjuki, L.J. Ann, M.A. Fazal, Corrosion characteristics of copper and leaded bronze in palm biodiesel, Fuel Process. Technol. 91 (2010) 329-334.

[3] A.S.M.A. Haseeb, H.H. Masjuki, C.T. Siang, M.A. Fazal, Compatibility of elastomers in palm biodiesel, Renew. Energ. 35 (2010) 2356-2361.

[4] W. Trakarnpruk, S. Porntangjitlikit, Palm oil biodiesel synthesized with potassium loaded calcined hydrotalcite and effect of biodiesel blend on elastomer properties, Renew. Energ. 33 (2008) 1558-1563.

[5] L. Treloar, The Physics of Rubber Elasticity. Oxford University Press, London, 1975.

[6] P. Flory, Principles of Polymer Chemistry. Cornell University Press, New York, 1953.

[7] W.D. Callister, Materials Science and Engineering: An Introduction, 7th ed. John Wiley \& Sons, 2007.
[8] W.V. Mars, Multiaxial fatigue of rubber, PhD thesis, University of Toledo, 2001.

[9] W.V. Mars, A. Fatemi, A literature survey on fatigue analysis approaches for rubber, Int. J. Fatigue 24 (2002) 949-961.

[10] E. Verron, A. Andriyana, Definition of a new predictor for multiaxial fatigue crack nucleation in rubber, J. Mech. Phys. Solids 56 (2008) 417-443.

[11] A. Andriyana, N. Saintier, E. Verron, Configurational mechanics and critical plane approach: concept and application to fatigue failure analysis of rubberlike materials, Int. J. Fatigue 32 (2010) 1627-1638.

[12] M. Brieu, J. Diani, C. Mignot, C. Moriceau, Response of a carbon-black filled SBR under large strain cyclic uniaxial tension, Int. J. Fatigue 32 (2010) 1921-1927.

[13] M. Abu-Abdeen, Single and double-step stress relaxation and constitutive modeling of viscoelastic behavior of swelled and un-swelled natural rubber loaded with carbon black, Mater. Design 31 (2010) 2078-2084.

[14] J. Magryta, C. Debek, D. Debek, Mechanical properties of swelled vulcanizates of polar diene elastomers, J. Appl. Polym. Sci. 99 (2006) 2010-2015.

[15] Y.S. Zuyev, S.I. Pravednikova, L.S. Zherebkova, V.D. Zaitseva, The tear-resistance of rubbers in the presence of physically aggressive media, Polym. Sci.. U.S.S.R. 5 (1964) 269-276.

[16] P.J. Flory, J. Rehner, Statistical mechanics of cross-linked polymer networks II. Swelling, Rubber Chem. Technol. 35 (1944) 521-526.

[17] S. Baek, A.R. Srinivasa, Diffusion of a fluid through an elastic solid undergoing large deformation, Int. J. Nonlin. Mech. 39 (2004) 201-218.

[18] W. Hong, X. Zhao, J. Zhou, Z. Suo, A theory of coupled diffusion and large deformation in polymeric gels, J. Mech. Phys. Solids 56 (2008) 1779-1793.

[19] C. Nah, G.-B. Lee, J.Y. Lim, Y.H. Kim, R. SenGupta, A.N. Gent, Problems in determining the elastic strain energy function for rubber, Int. J. Nonlin. Mech. 45 (2010) 232-235.

[20] J.S. Soares, Diffusion of a fluid through a spherical elastic solid undergoing large deformations, Int. J. Eng. Sci. 47 (2009) 50-63.

[21] S.A. Chester, L. Anand, A coupled theory of fluid permeation and large deformations for elastomeric materials, J. Mech. Phys. Solids 58 (2010) 1879-1906.

[22] F. Duda, A. Souza, E. Fried, A theory for species migration in a finitely strained solid with application to polymer network swelling, J. Mech. Phys. Solids 58 (2010) 515-529.

[23] A.N. Gent, Engineering with Rubber. How to Design Rubber Components, 2nd ed. Hanser, 2001.

[24] S.C. George, S. Thomas, Transport phenomena through polymeric systems, Prog. Polym. Sci. 26 (2001) 985-1017.

[25] K. Fukumori, T. Kurauchi, O. Kamigaito, Swelling behaviour of rubber vulcanizates: 2 . Effects of tensile strain on swelling, Polymer 31 (1990) 2361-2367.

[26] S.C. George, M. Knörgen, S. Thomas, Effect of nature and extent of crosslinking on swelling and mechanical behavior of styrenebutadiene rubber membranes, J. Membrane Sci. 163 (1999) 1-17.

[27] J.S. Bergström, M.C. Boyce, Constitutive modeling of the large strain time-dependent behavior of elastomers, J. Mech. Phys. Solids 46 (1998) 931-954.

[28] A. Lion, On the large deformation behaviour of reinforced rubber at different temperatures, J. Mech. Phys. Solids 45 (1997) 1805-1834.

[29] S. Trabelsi, P. Albouy, J. Rault, Crystallization and melting processes in vulcanized stretched natural rubber, Macromolecules 36 (2003) 7624-7639.

[30] H. Bouasse, Z. Carrière, Courbes de traction du caoutchouc vulcanisè, Ann. Fac. Sci. Toulouse 5 (1903) 257-283.

[31] L. Mullins, N.R. Tobin, Theoretical model for the elastic behavior of filler-reinforced vulcanized rubbers, Rubber Chem. Technol. 30 (1947) 551-571.

[32] J. Diani, B. Fayolle, P. Gilormini, A review on the Mullins effect, Eur. Polym. J. 45 (2009) 601-612. 